\title{
Correlative Study between UV Irradiance and TOC Using AURA OMI at Kannur (12.3N, 75.4E)
}

\author{
Nishanth T. ${ }^{*}$, Sheela M. Joseph, Praseed K. M., M. K. Satheesh Kumar \\ Department of Atmospheric Science, Kannur University, Kannur, Kerala, India \\ E-mail: nisthu.t@gmail.com \\ Received February 25, 2011; revised March 8, 2011; Accepted March 15, 2011
}

\begin{abstract}
The solar UV radiation has prominent impacts on human life, animals and plants with positive and negative effects. Atmospheric ozone, which is formed from the photodissociation of molecular oxygen mainly in the stratosphere, absorbs a significant factor of solar UV radiation. The ozone in the stratosphere acts as a protective layer to prevent UV radiation reaching on the surface of the earth. Hence the intensity of solar UV radiation on the surface has a strong dependence on the Total Ozone Column (TOC). The UV irradiance on earth surface depends on geometrical factors such as solar zenith angle, altitude, latitude and other atmospheric parameters as well. This is an attempt to study the variation of solar UV flux at its four discrete wavelengths ranging from 305 - $380 \mathrm{~nm}$ at Kannur, which is located in the north of Kerala in India. Hence such a correlation of TOC and UV irradiance is relevant to realize the radiation budget at this location (12.3N, 75.4E) using AURA OMI data. This paper reveals the correlation of day to day, month to month temporal variation of total ozone column (in DU) and UV irradiance $\left(\mathrm{w} / \mathrm{m}^{2}\right)$. From the analysis, the anti-correlation between UV and TOC is revealed and its impact in the solar radiation budget is established.
\end{abstract}

Keywords: UV Irradiance, Aura OMI, Total Ozone Column, Sun Burn

\section{Introduction}

Ozone is an important atmospheric constituent, because it absorbs the part of solar radiation that is deleterious to biological life on earth [1]. It is also widely accepted that although UV irradiance represents a small portion of the solar spectrum, its spatial and temporal availability is of great importance [2]. This is because UV is responsible for a variety of familiar photochemical reactions, including photochemical smog in polluted urban areas, bleaching of paints, decay of plastics and other detrimental effects on the earth's ecosystems [3-6]. The solar UV radiation is classified as UV-A (320 - $400 \mathrm{~nm})$, UV-B (280 - $320 \mathrm{~nm}$ ) and UV-C (200 - $280 \mathrm{~nm})$, based on the wavelength of the radiation. While the UV-C radiation is completely absorbed by the atmospheric ozone, most of the UV-A radiation reaches the earth's surface. The UV-A radiation is however, not harmful to biological life on earth [7]. UVB (spectral range $280-320 \mathrm{~nm}$ ) still reaches ground level it is strongly absorbed by stratospheric ozone. UV- B radiation is effectively attenuated by the stratospheric ozone layer, it is not fully blocked. It is very strongly absorbed in tissues and penetrates only superficially into the body; thus it directly affects only the eye and the skin. Detrimental consequences for the eye could include impaired vision, since UV radiation has been reported to cause opacification of the lens (cataract), losses of productivity and other destructive effects in plants [8-12]. Quite apart from its damaging effects, the UVB can also be beneficial; it initiates the production of vitamin $\mathrm{D}$ that helps build and maintain human bones as well as it may prevent against certain types of cancer [4, 13]. Although UVB comprises the most energetic wavelengths, several studies showed that UVA is also hazardous, producing skin damage and premature skin photo-ageing and wrinkling as well as eye damage.

The total column ozone at a location is known to vary from day to day, seasonally and annually. Periodicity related to quasi-biennial and solar cycles has also been associated with the total column ozone variation [14]. UV-B radiation is strongly absorbed by stratospheric ozone, and its intensity at the surface depends on the ozone layer concentration $[15,16]$.

Studies on stratospheric ozone depletion at many locations on the globe are being made using instruments like 
the Dobson spectrophotometer, Brewer spectrophotometer etc. In addition to these ground based ozone measurements, which have limited spatial coverage, measurements done by Total Ozone Mapping Spectrometer (TOMS) aboard Nimbus-7 Satellite provide a good database for the long-term monitoring of column ozone with extensive spatial coverage. Krishna Prasad and Niranjan [17] made an attempt to study the correlation between solar UVB irradiance and total column ozone with TOMS data. They made regression model for estimating UV-B irradiance from TOMS ozone, air-mass, sun-earth distance correction and solar zenith angle at Vishakhapatnam. In addition to this, they studied a long-term variation of incoming UV-B irradiance for the period 1978-1993 using TOMS ozone. The main objective of this work is to analyze the correlation between clear sky UV irradiance and total ozone column using AURA OMI over Kannur at different season of 2009.

\section{Results and Discussion}

\subsection{Ultra Violet (UV) Irradiance and Total Ozone Column (TOC)}

The UV irradiance and TOC data sets consists of observations carried out by satellite borne instrumentation (TOMS and OMI). The Total Ozone Mapping spectrometer (TOMS) launched on board the Earth Probe satellite of NASA in July 1996 is still continuing by long term daily mapping of the global distribution of the distribution of ozone over a column of atmosphere. The Ozone Monitoring Instrument (OMI) has been operating since July 2004 on board EOS Aura which is a nadir viewing imaging spectrograph that measures solar radiation back scattered by earth atmosphere and surface over the wavelength range from $300 \mathrm{~nm}$ to $500 \mathrm{~nm}$ with a spectral resolution of about $0.5 \mathrm{~nm}$. In this study, data were retrieved only at cloudless, blue-sky conditions at similar solar zenith angles to eliminate much of the influences of non- ozone parameters described earlier. The UV irradiance and TOC were analyzed at pre monsoon (May), monsoon (June), post monsoon (October) and winter (December) seasons in Kannur. The relation connecting solar irradiance and total ozone column is depicted in the Figure 1. The data is taken in a clear sky days of the months of May 2009 for a wavelength of 305 $\mathrm{nm}$ with a solar zenith angles of 25.07, 22.33, 24.02, and 30 . From the figure, it is clearly seen that both solar irradiance and total ozone column are anti correlating with each other.

The data correspond to $305 \mathrm{~nm}$ solar irradiance and respective total ozone column were analyzed in detail in a pre-monsoon (May), post monsoon (October), monsoon (June) and winter (December) season of 2009 and is shown in the following Figures 2-5.

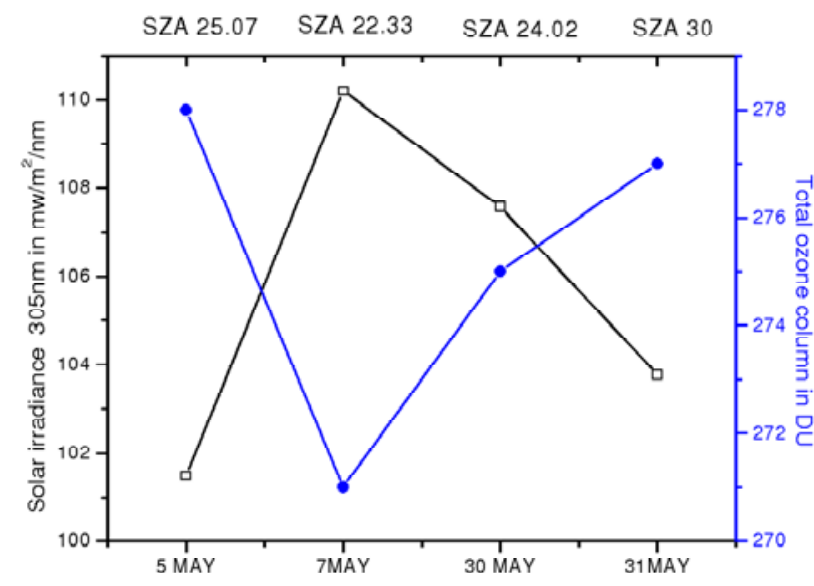

Figure 1.Variation of clear sky irradiance with TOC.

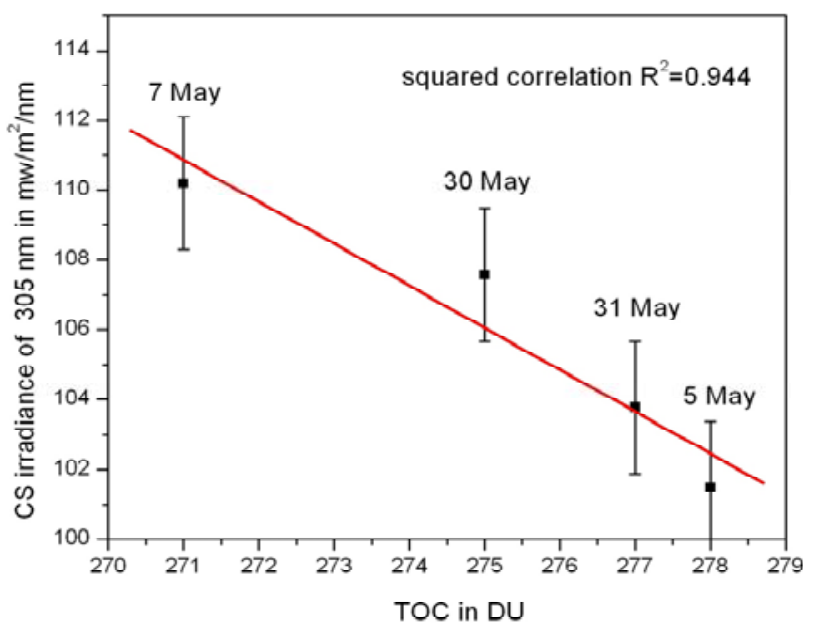

Figure 2. Correlation between TOC and CS irradiance for $305 \mathrm{~nm}$ in pre monsoon months (May) 2009.

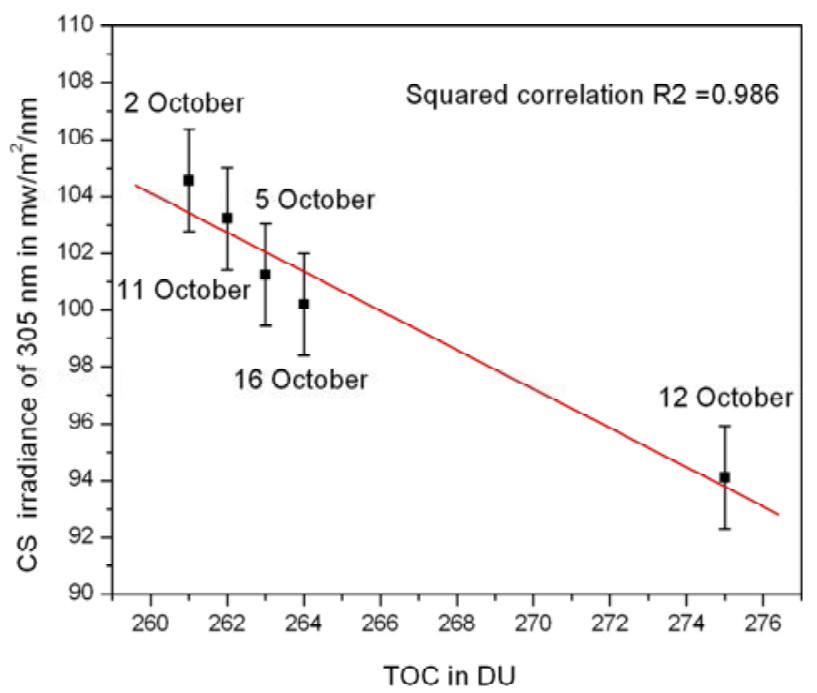

Figure 3. Correlation between TOC and CS irradiance for $305 \mathrm{~nm}$ in post monsoon months (October) 2009. 


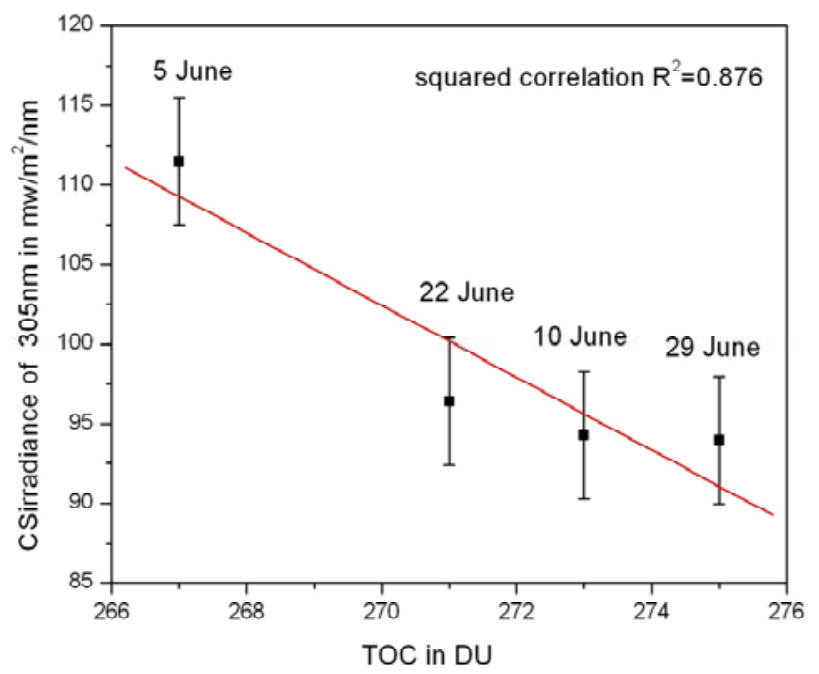

Figure 4. Correlation between TOC and CS irradiance for $305 \mathrm{~nm}$ in monsoon months (June) 2009.

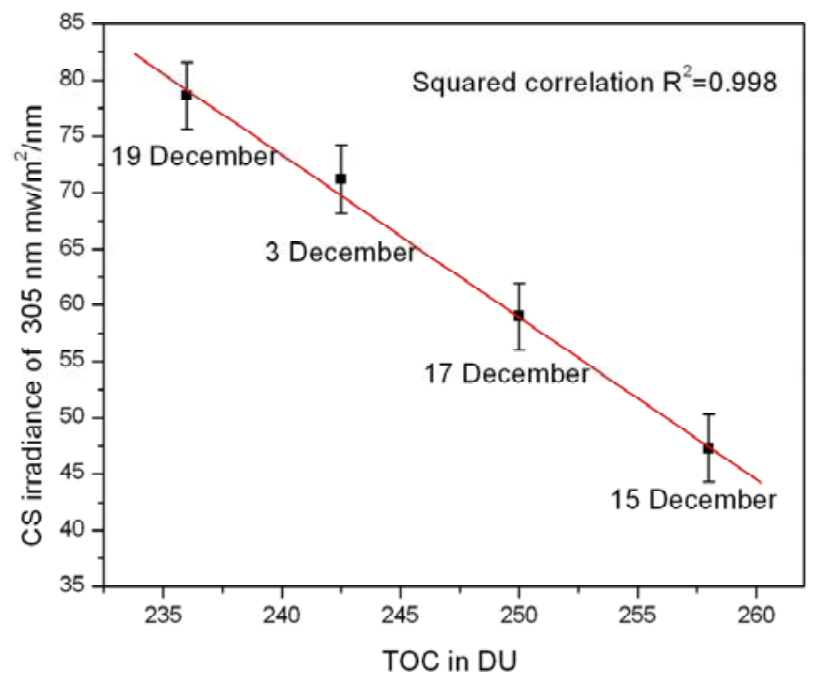

Figure 5. Correlation between TOC and CS irradiance for $305 \mathrm{~nm}$ in winter months (December) 2009.

In the Figure 2, it is seen that the CS irradiance and total ozone column are anti correlate with each other and the correlation coefficient is -0.958 . The squared correlation between clear sky irradiance and total column ozone for $305 \mathrm{~nm}$ is 0.944 .

In the Figure 3 it is clear that the effective UVB and total ozone column are anti correlate with each other and the correlation coefficient $(r=-0.972)$ is statistically significant, probably due to the same aerosol optical thickness. The squared correlation between clear sky irradiance and total column ozone for $305 \mathrm{~nm}$ is 0.986 . This means that a change in 100DU ozone produces about $70 \mathrm{mw} / \mathrm{m}^{2}$ effective UV.

In the Figure 4, the effective UVB and total ozone column are anti correlate with each other and the correlation coefficient $(r=-0.92)$ is statistically significant but the squared correlation $\left(R^{2}=0.876\right)$ is not good. This may be due to the aerosol optical thickness effect or due to the cloud effect or humidity. This means that a change in $100 \mathrm{DU}$ ozone produces about $200 \mathrm{mw} / \mathrm{m}^{2}$ effective UV. The correlation is not good.

In the Figure 5, the effective UVB and total ozone column are still anti correlate with each other and the correlation coefficient $(\mathrm{r}=-0.999)$ is statistically significant probably due to the same aerosol optical thickness. The squared correlation is also statistically important $\left(\mathrm{R}^{2}=0.998\right)$ this means a change in $100 \mathrm{DU}$ ozone column reduces about $110 \mathrm{mw} / \mathrm{m}^{2}$ effective UV.

Table 1 shows the correlation coefficient and the squared correlation between clear sky irradiance and total ozone column for $305 \mathrm{~nm}$ for different seasons of observation.

\subsection{Total Ozone Column over Kannur}

The monthly mean value of total ozone column over Kannur was retrieved from TOMS and is plotted against the months for the year Jan 2000 to February 2010. The variation of total ozone column over Kannur during 2000-2010 is shown in the Figure 6.

Total ozone columns are generally measured in Dobson Unit. One Dobson is $2.69 \times 10^{16}$ ozone molecules $/ \mathrm{cm}^{2}$. When the total ozone column is less than $220 \mathrm{DU}$, there is chance for the production of ozone hole in that location.

Table1. Seasonal variation of correlation coefficient and $\mathbf{R}^{2}$.

\begin{tabular}{ccc}
\hline Season & $\begin{array}{c}\text { Correlation } \\
\text { coefficient }\end{array}$ & Squared correlation $\left(\mathrm{R}^{2}\right)$ \\
\hline Pre monsoon & -0.958 & 0.954 \\
Monsoon & -0.921 & 0.876 \\
Post monsoon & -0.972 & 0.986 \\
Winter & -0.999 & 0.998 \\
\hline
\end{tabular}

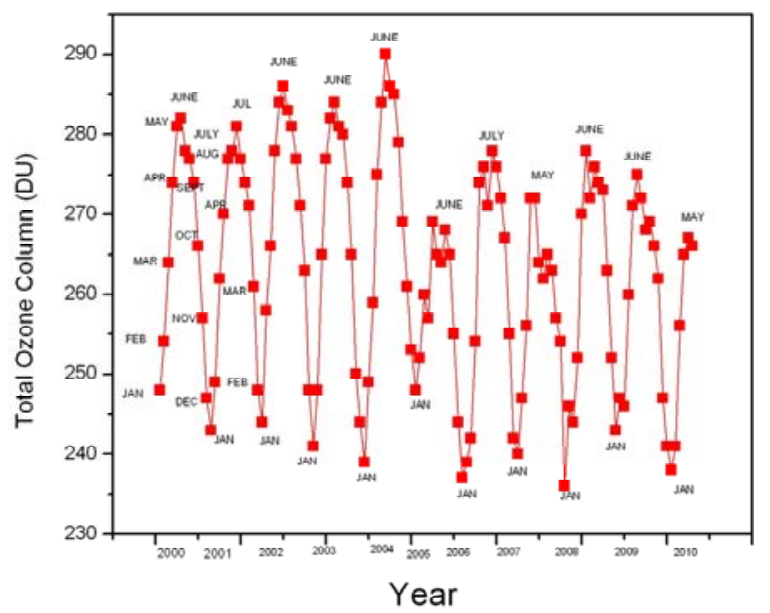

Figure 6. Variation of total ozone column over Kannur during 2000-2010. 
From the figure it is clear that the total ozone concentration is found to be high in May and June. It decreases during monsoon and becomes very low in December and January. Thereafter it gradually increases throughout the winter reaches a peak in summer. This trend is consistently observed in all the years from 2000 to 2010. The amount of ozone in the troposphere and lower stratosphere in general depends on both dynamics and chemistry of the atmosphere. The dynamical influences include wave driving of the stratospheric circulation and tropopause folds. The only mechanism of ozone production is the recombination of atomic oxygen with oxygen molecules. In the troposphere the energetically excited oxygen atom is comes from the photodissociation of $\mathrm{NO}_{2}$, whereas in the stratosphere it comes from the dissociation of oxygen molecules. There is a sharp decrease in total ozone column was observed in the year 2005. This may be due to the fact that the year 2005 was the hottest year of this decade. Subsequently, the convective activity increases and the ozone are removed from the atmosphere due to this enhanced convective activity.

\subsection{Tropospheric Ozone over Kannur}

Even if about $90 \%$ of atmospheric ozone molecules reside in the stratosphere, tropospheric ozone strongly influences the radiative budget of the atmosphere and the oxidation capacity of the troposphere. Due to its high chemical reactivity in the lower troposphere, ozone is considered a dangerous pollutant, causing harm to human health and ecosystems. Figure 7 shows the variation of tropospheric ozone over Kannur during 2005 to 2010, retrieved from Aura OMI.

From the figure it is clear that tropospheric ozone concentration is high during summer (March, April, May) and low during monsoon (July, August, September)

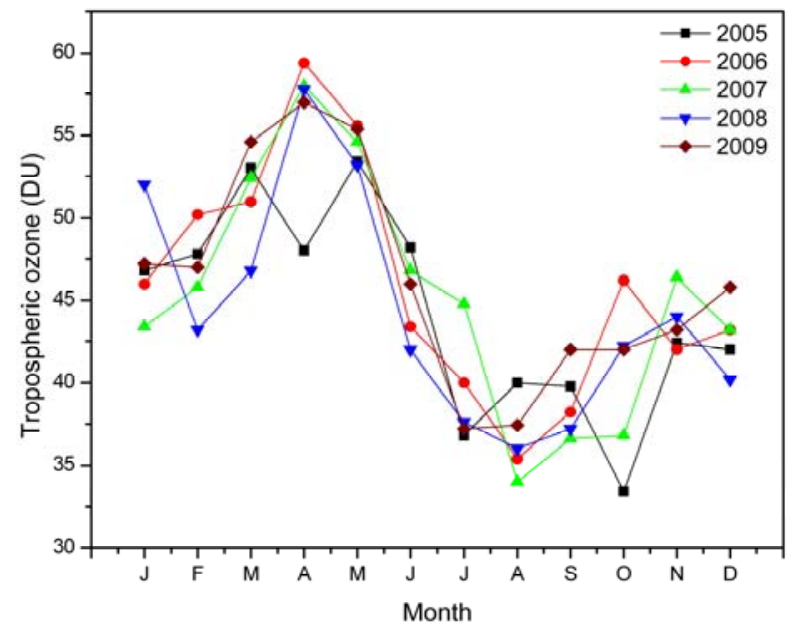

Figure 7. Variation of tropospheric ozone over Kannur during 2005-2005. seasons. Maximum concentration of 59.4 DU is observed in April 2006 and a minimum of 34 DU is observed in August 2007.During the period of observation it is found that an increase of $4.17 \%$ of tropospheric ozone over Kannur.

\subsection{Uv Index During Sun Burn}

The UV index is an international standard measurement of how strong is the ultraviolet (UV) radiation from the sun at a particular place on a particular day. It is a number linearly related to the intensity of UV radiation reaching the surface of the earth at a given point. It cannot be simply related to the irradiance (measured in $\mathrm{W} / \mathrm{m}^{2}$ ) because the UV of concern occupies a spectrum of wavelength from $295 \mathrm{~nm}$ to $325 \mathrm{~nm}$ and shorter wavelengths have already been absorbed a great deal when they arrive at the Earth's surface. Skin damage, however, is related to wavelength, the shorter wavelengths being much more significant. Variation of Erythemal UV over Kannur is shown in the Figure 8.

The monthly mean UV values have been retrieved over Kannur from the TOMS EP data and from OMI Aura. Data are plotted against months for the years January 2000 to February2010. It shows a clear seasonal variation that is repeated consistently year after year. It is further observed that the UV at Kannur has increased consistently from 2000 to 2010. There is a sharp increase in UV In the year 2005. This shows that total ozone column has a significant effect on the UV radiation. Table 2 shows the average value of total ozone column observed during the month of March 2005-2010 at Kannur and Palakkad in Kerala, India where the sun burn was reported in month of March 2010.

From the above table, it is clear that the total ozone column during March is quite low as compared other

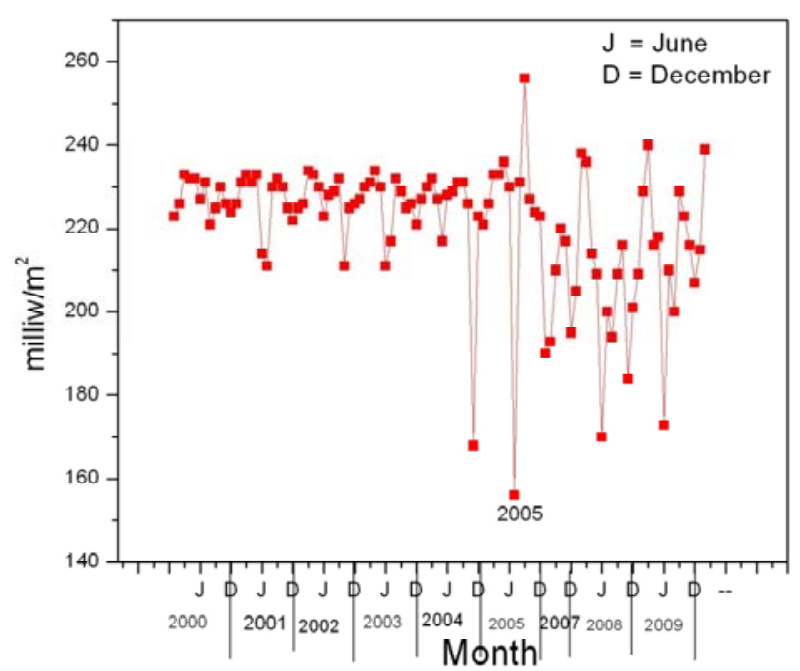

Figure 8. Variation of Erythemal UV over Kannur. 
Table 2. Variation of TOC over Kannur and Palakkad.

\begin{tabular}{ccc}
\hline \multirow{2}{*}{ Year } & \multicolumn{2}{c}{ Location where sun burn reported } \\
\cline { 2 - 3 } & Kannur (TOC DU) & Palakkad (TOC DU) \\
\hline 2005 & 259 & 257 \\
2006 & 254 & 253 \\
2007 & 255 & 254 \\
2008 & 251 & 250 \\
2009 & 260 & 260 \\
2010 & 250 & 246 \\
\hline
\end{tabular}

months in Kannur. Generally, TOC over Palakkad is lesser than that of Kannur. Comparing to other year, during 2010 total ozone column is very low over Kannur and Palakkad. This may be the prime reason for the sun burn reported in these two locations.

\section{Conclusions}

The solar UV irradiance on clear sky days during pre-monsoon, monsoon, post-monsoon and winter seasons has been successfully retrieved from OMI and this has been correlated with total ozone column over Kannur. As expected a negative correlation is obtained between UVB and TOC in all season. However, the correlation is much strong during post-monsoon and winter days due to relatively clean atmosphere after severe south west monsoon activity in Kannur. During the pre monsoon and monsoon period, the atmosphere becomes quite turbid due to heavy winds that transport aerosols and trace gases that make the degree of correlation relatively poor. Thus it is evident that the correlation of solar UV irradiance with changes in TOC becomes more accurate during post monsoon and winter months over Kannur. The extended study revealed a significant reduction in TOC over some regions in Kerala from where few cases of sun burn have been reported during March. This reduction of total ozone column enhanced the amount of UVB flux more than the normal dose and this is the prominent cause for the sunburn cases reported from these locations in the state.

\section{Acknowledgements}

Authors acknowledge their deep sense of gratitude to Kannur University for providing all support to materialize this target. One of the authors Sheela M Joseph expresses her sincere thanks to Dr.Suriya Ahmad, NASA and Dr.Anitti Arola, Finland Meteorological Institute, Finland for their help and support received in retrieving and analyzing TOMS data.

\section{References}

[1] Crutzen, P. J., The influence of nitrogen oxides on at- mosphere ozone content. Q. J. R. Meteorol. Soc., 1970, 96, 320-325.

[2] Stolarski, R. S. and Cicerone, R. J., Stratospheric chlorine: A possible sink for ozone. Can. J. Chem., 1974, 52, 1610-1615.

[3] de Gruijl, F.R., van der Leun, J.C., 2000. Environment and health: 3-Ozone depletion and ultraviolet radiation. CMAJ 163 (7), 851-855.

[4] Heisler, G.M., Grant, R.H., 2000. Ultraviolet radiation in urban ecosystems with consideration of effects on human health. Urban Ecosyst. 4, 193-229.

[5] McKenzie, R.I., Bjorn, L.O., Bais, A., Ilyasd, M., 2003. Changes in biologically active ultra violet radiation reaching the Earth's surface. Photochem. Photobiol. Sci. 2,5-15.

[6] Jacovides, C.P, Tymvios , F.S, Asimakopoulos D.N, Kaltsounides N.A. Theoharatos G.A. Tsitouri M , Solar global UVB (280 - $315 \mathrm{~nm}$ ) and UVA (315 - $380 \mathrm{~nm}$ ) radiant fluxes and their relationships with broadband global radiant flux at an eastern Mediterranean site, Agricultural and Forest Meteorology 149 (2009) 1188-1200

[7] Molina, M. J. and Rowland, F. S., Stratospheric sink for chlorofluromethanes: Chlorine catalyzed destruction of ozone. Nature, 1974, 249, 810-814.

[8] Setlow, R.B., 1974. The wavelengths in sunlight effective in producing skin cancer: a theoretical analysis. Nat. Acad. Sci. U.S.A. 71 (9), 3363-3366.

[9] Webb, A.R., Steven, M.D., 1986. Daily totals of solar UVB radiation estimated from routine meteorological measurements. J. Climatol. 6, 405-411.

[10] Day, T.A., Ruhland, C.T., Grobe, C.W., Xiong, F., 1999. Growth and reproduction of Antarctic vascular plants in response to warming and UV radiation reductions in the field. Oecologia 119, 24-35

[11] McKenzie, R. L., Bjorn, L. O. , Bais A. and Ilyas, M. Changes in Biologically active ultraviolet radiation reaching the Earth's surface, Photochem. Photobiol. Sci., (2003), this issue (DOI:10.1039/b21155c).

[12] Parisi, A.V., Turnbull, D.J., Turner, J., 2008. Comparison of biologically effective spectra for erythema and pre-vitamin D3 synthesis. Int. J. Biometeorol., doi:10.1007/s00484-008-0186-z.

[13] Turnbull, D.J., Paris, A.V., Kimlin, M.G., 2005. Vitamin $\mathrm{D}$ effective ultraviolet wavelengths due to scattering in shade. J. Steroid Biochem. Mol. Biol. 96, 431-436.

[14] Ferman, J. C., Gardner, B. G. and Shanklin, J. D., Large loses of total ozone in Antarctica reveal seasonal ClOx/NOx interactions. Nature, 1985, 315, 207-210.

[15] Madronich SRL, Mickenzie LO, Bjorn and Calwell MM, 1998.Changes biologically active ultravilot radiation reaching the Earths surface.J. Photochem. Photobiol., 46,5-19.

[16] N.N Purkait etal -Effective UV irradiance and total ozone column - A case study using data from TOMS and Micro top sun photometer.J. Radio\& Space Physics 38(2009) pp 86-97 
[17] Krishna Prasad NV and Niranjan K, Solar UV-B Irradiance at a tropical Indian station Visakhapatnam $\left(17.70^{\circ}\right.$
North, $83.30^{\circ}$ East) - a Relation with TOMS Ozone, TAO, Vol. 16, No. 1, 215-229, March 2005 